\title{
and Assessment Rrogramme min
}

by Lars-Otto Reversen,

Ramon Guardans, and Leiv K. Sydnes

fter World War II, the Cold War generated significant barriers between the East and the

West, and this affected all sorts of cooperation, including research and scientific collaboration. However, as the political situation in the Soviet Union started to change in the 1980s under the leadership of Mikael Gorbachev, the environment for international collaboration in many areas gradually improved.

This became quite visible in the Arctic, and the reason for this has often been ascribed to a visionary speech given by Gorbachev in Murmansk (Russia) in 1987 where he called for development and implementation of a new policy with a number of political goals, including:

- a Northern Europe free of nuclear weapons;

- reduction of military activity in the region and promotion of military trust;

- cooperative development of Arctic resources and opening up of the north-eastern sea route to international shipping;

- development of a comprehensive plan, including a monitoring program, to protect the Arctic environment.

This invitation was quickly picked up by the Finnish government, which challenged Canadian authorities to take the lead and launch a process to implement some of the proposals made in the Murmansk speech. This generated a lot of diplomatic activity among the eight Arctic states (Canada, Denmark, Finland, Iceland, Norway, Sweden, the Soviet Union, and the United States), and many initiatives were explored and discussed. At a meeting in Rovaniemi (Finland) in 1989, it was concluded that there was no international structure with the capacity to coordinate effective environmental cooperation in the Arctic, and it was therefore decided to develop an international body that would be in charge of and coordinate a program to monitor the environmental status and development in the Arctic (Stone, 2015). Such a body would need a solid political platform, and this gradually emerged and led first (1991) to the development of the Arctic Environmental Protection Strategy (AEPS) and subsequently (1996) to the formation of the Arctic Council (AC). This Council is led by the ministers of foreign affairs from the Arctic countries and is today the key political body for the Arctic.

With the AEPS agreement in place, the Arctic Monitoring and Assessment Programme (AMAP, www. amap.no) was launched with the aim of implementing the AEPS. In practical terms, the task was to monitor and assess the levels, trends, and effects of pollutants and climate change on the Arctic ecosystem and the people living there, especially the indigenous peoples. The work was coordinated by a secretariat located in Oslo (Norway), first working as part of AEPS, but from 1996 under the umbrella of the Arctic Council.

From the outset, AMAP was given a wide mandate, namely to study the trends and effects of anthropogenic pollutants in all compartments of the Arctic environment irrespective of their sources. The lack of any source restriction was very important because it included contaminants of both civilian and military origin. Based on scattered studies from the 1970s and 80 s, the program was specified to focus on persistent organic pollutants (POPs), heavy metals, radionuclides, acidification of land and freshwater, petroleum hydrocarbons, and climate change, and at the same time looking-up for emerging issues.

\section{The AMAP approach and method}

In November 1991, the AMAP Task Force met for the first time, and at this meeting, Rules of Procedure and variables essential for the assessment were approved.

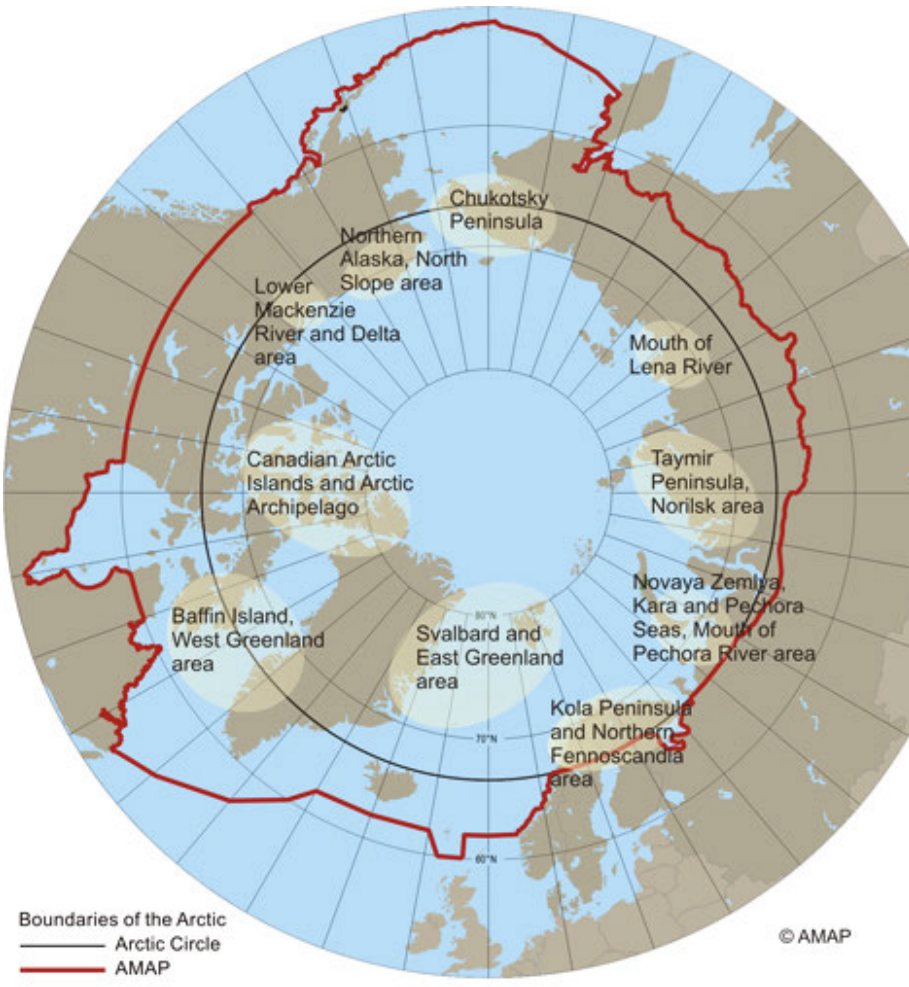

Figure 1. The geographic area for the AMAP

monitoring programme; reproduced from

https://www.amap.no/about/geographical-coverage 
It was also decided that the monitoring should be coordinated with existing international programs and based on standardized methodologies. And finally, only results published in scientific journals with an independent peer-review system in place, or new data collected in accordance with an adopted strict quality assurance/quality control ( $Q A / Q C)$ system for planning, sampling, extraction, analyses, and data handling.

An important task in the establishment of AMAP was capacity building to make sure that the QA/QC system could be, and indeed was, followed. In some cases, no approved methodology existed for the analysis of specific compounds of interest, e.g. for some of the POPs, and in such cases, experts in POP analysis were asked to develop and publish approved methods that were then adopted as AMAP methodology. In order to improve the quality of the analyses, international inter-calibration exercises were also implemented. In cooperation with Canada, AMAP established two new inter-calibration systems for POPs, one for human-blood samples and another for various samples from Arctic animals, and when in place, laboratories had to achieve an acceptable intercalibration score to become approved AMAP laboratories for such analyses.

In 1994 AMAP decided to start the work with a comprehensive report about the work carried out and the main results. A team of about 100 scientists and experts nominated by the Arctic countries, observing countries, international organizations, and representatives for the Arctic indigenous peoples (permanent participants) carried out the task and produced a 860page assessment report, AMAP Assessment Report (AAR), which was published in 1998 after a thorough peer-review process, first a "friendly" process to make sure that the scientists that had provided the data accepted the assessment and then an international independent peer review. In addition, a layman-style publication, Arctic Pollution Issues: A State of the Arctic Environment Report (SOAER) (AMAP, 1997), written in plain language to be suitable for politicians and the public, was published and translated into eight languages, including the Saami language. The geographical area covered by AMAP is shown in Figure 1.

When AMAP started the work, it was rather seldom that scientists would report results back to the people living in the area where the samples had been collected. However, early on AMAP adopted this practice, particularly on issues related to human health which were done in close cooperation with local health-care personnel and local indigenous organizations.

\section{AMAT OUtConnes}

\section{Radioactivity}

In 1994, AMAP established an expert group with specialists from Russia, Norway, Sweden and Finland, to perform an assessment of radioactive "hot spots" in North-West Russia. The 1995 report from the group documented threats from several sources and recommended several actions for cleanup. In January 1996 the report was presented to the International Atomic Energy Agency (IAEA) in Vienna, and the following years a significant amount of work was carried out to clean-up contaminated sites and improve the security in operation of nuclear power plant at Kola Peninsula. Also, all except one of the 198 Russian nuclear submarines taken out of service since in 1994 have been decommissioned, nuclear waste storage sites cleaned up, and several hundred lighthouses previous driven by radioisotope thermonuclear generators have been replaced by solar power devices.

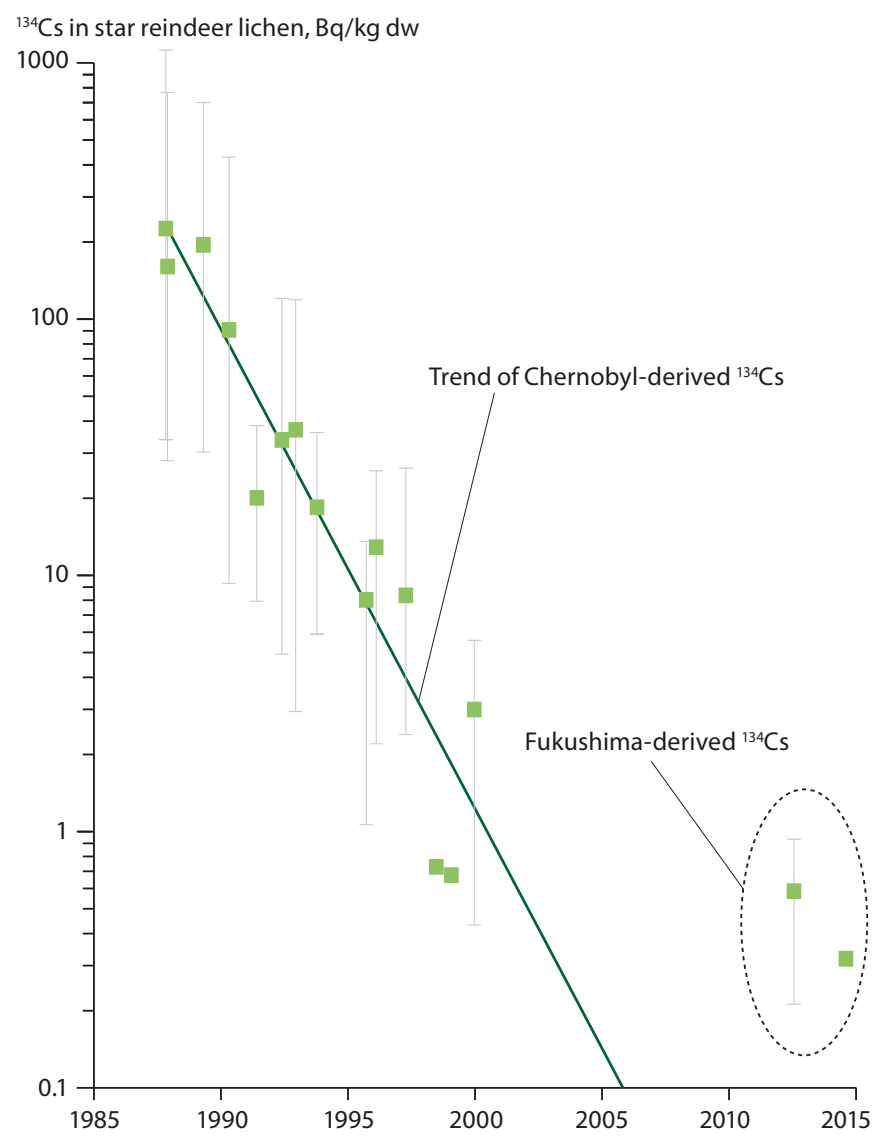

Figure 2. Levels of radioactive cesium observed at an Arctic location in Finland due to releases from Chernobyl and Fukushima. (AMAP, 2016. AMAP Assessment 2015: Radioactivity in the Arctic.) 
Later assessments have confirmed that traces of radionuclide depositions from testing of atomic weapons and the Chernobyl accident still can be detected in the Arctic (AMAP, 2009 \& 2015). It has also been documented that the ${ }^{137} \mathrm{Cs}$ in the Barents Sea in the 1970s did not come from Soviet Union, but from the Sellafield reprocessing plant in the UK, and it was also proved that radioactive iodine came from Cap de la Hague in France. Based on these observations Nordic countries put political pressure on the UK to stop the discharges, and over the years the situation has changed to the better. The accident at Fukushima, Japan (2011) affected mainly marine areas around Japan, but traces have been detected in the Arctic marine environment (Figure 2). Another contaminated area is the sea around the Thule airbase in Greenland; here there is still plutonium equivalent to one nuclear bomb present (www.amap.no).

\section{Acidification and Arctic Haze}

In the 1970s, acidification of land and freshwater due to atmospheric emission of $\mathrm{SO}_{2}$ was high on the environmental political agenda in Europe and North America and this parameter was included in the AMAP program as well. AAR 1998 documented some ecosystem effects due to acidification in northern Scandinavia, especially on forest, but this was not due to longrange transportation from central Europe; the effect was rather caused by impact from some large smelters in the northwest part of the Soviet Union. The second report on acidification, published in 2006, showed that the atmospheric concentration and deposition of acidifying chemicals had decreased significantly, and further monitoring and assessment of acidification under AMAP was therefore put to a hold.

\section{Persistent Organic Pollutants (POPs)}

Monitoring of POPs was a key objective in AMAP from the very beginning. An important reason for that was the results from a major Canadian investigation, performed in the 1980s, of the levels of some metals and POPs, such as PCBs and toxaphene, in the diet, blood, and breast milk of Inuits; it documented clearly levels of PCBs comparable to or above those found for populations in urban and industrialized sites in Canada (Stone, 2015). This study was followed up in 1990, when the Canadian federal government announced a new environmental program, the "Northern Contaminate Programme", directed towards monitoring contaminants in the food consumed by indigenous people living in the Arctic; the results from this study confirmed the results from the ' 80 s.

In the beginning of the 1990s the only international agreements that could possibly deal with POPs were the Basel Convention (1989) on chemical waste, and the Geneva Convention on Long-Range Transboundary of Air Pollution (LRTAP) (1979), a regional agreement covering Europe and North America. Monitoring in the Canadian Arctic had been initiated under both conventions, but when the AMAP initiative started to materialize, a major well-coordinated international program involving several Arctic countries was launched under the auspices of the AMAP umbrella.

The collective aim of this monitoring program was to address several important questions: How are POPs

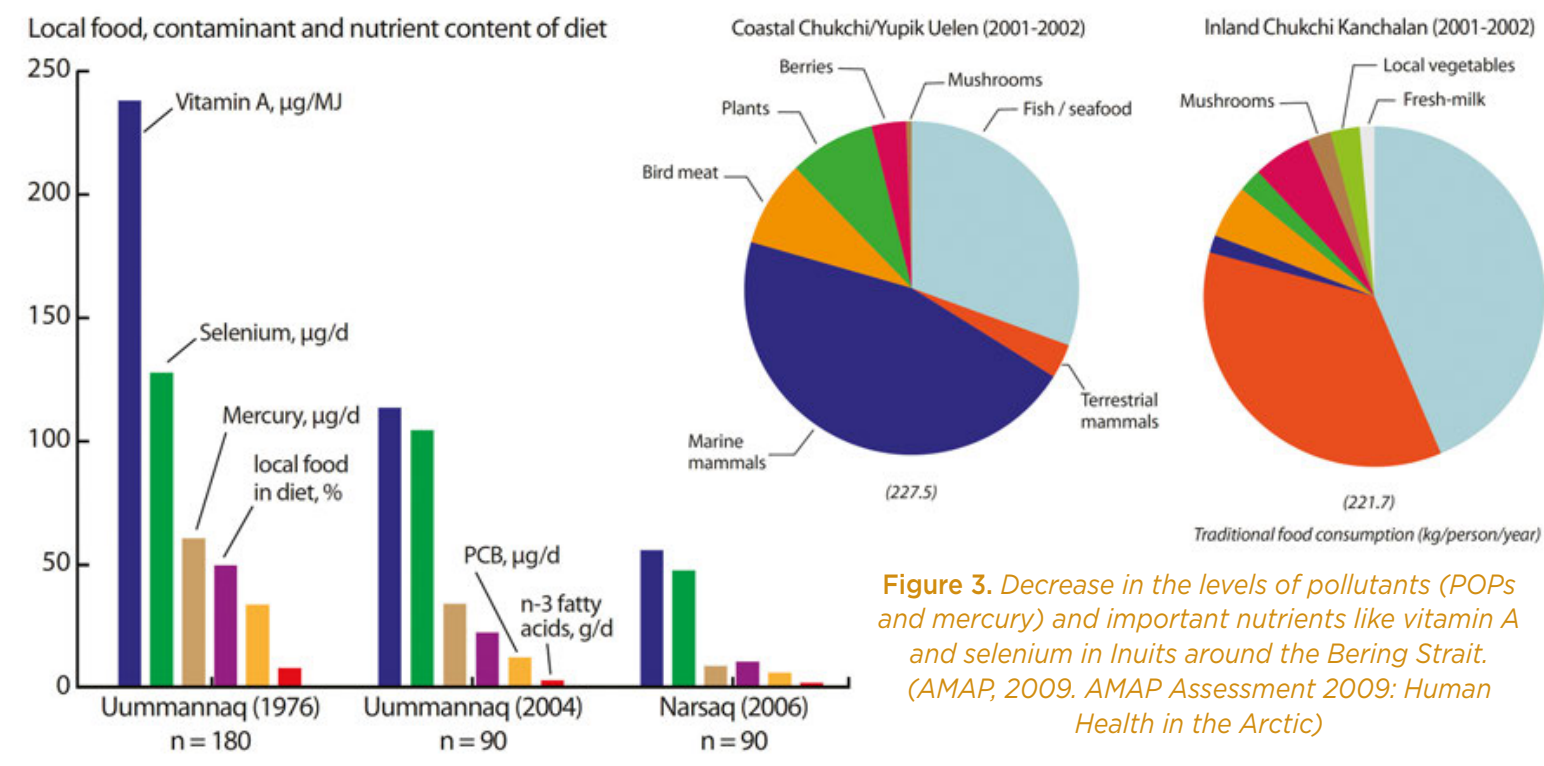


moving from their sources to the Arctic? Are POPs accumulating in organisms, ecosystems, and people? Is the POP input mostly attributable to atmospheric long-range transport? Results quickly emerged and at an AMAP international conference in 1997, new results on POPs documented that some of the levels found in Arctic animals were comparable to effect levels found in laboratory studies.

The results presented by AMAP made headlines globally and had quickly a significant impact. In 1997, the Governing Council of the United Nations Environmental Program (UNEP) decided to establish an International Negotiating Committee (INC) with the mandate to develop and propose a legally binding instrument for launching international actions to regulate and curb the use of 12 specific POPs. Based on input from an international group of experts and the scientific community at large, progress was gradually made, and in 2001 the negotiations were completed. The outcome was the Stockholm Convention (SC), which has been presented in detail in a previous issue of this magazine (Fiedler et al., 2019). Today this global convention has listed some 30 groups of substances and 183 parties are signatories, with the notable exceptions of the USA and Greenland! An important innovation in the SC was the evaluation instrument, which is applied to assess the progress made by the parties to the convention in their work to reduce their use and release of POPs.

On the basis of this work, a Global Monitoring Plan (GMP) on POPs was published in 2004, and later updates have definitely contributed positively to reduce the use of these compounds (Daniel et al., 2018). The latest AMAP and GMP reports on POPs have documented a positive trend for some of the compounds of concern in the sense that their levels have been reduced both in Arctic ecosystems and in humans living in the region, see Figure 3 . This can in part be attributed to reduced use and emissions caused by stricter regulations, enhanced awareness, and changed diets, that also may have affected intake on intake of vitamins from traditional food, e.g. sea mammals.

It has been noted that specific regulations can lead to significant progress relatively quickly, but the time lag between early warning and effective implementation of regulations can also be 30-40 years (Guardans, 2012). A serious concern today is that new substances are released from new sources, and some of these compounds behave like some of the classical POPs. The increasing presence in the Arctic of new POPs and new substances that behave like POPs is of emerging concern, see Figure 4.

\section{Chemicals of Emerging Arctic Concern}

- Per-polyfluorinated compounds (PFCAs, PFSAs, etc.)

- Brominated flame retardants (BDE-209, HBCD, DPTE, etc.)

- Organophosphate-basedflame retardants and plasticisers (TnBP, TCEP, TCPP, TDCPP, etc.)

- Phthalates

- Short-chained chlorinated paraffins

- Siloxanes

- Pharmaceuticals and personal care products

- Polychlorinated napthalenes

- Hexachlorobutadiene

- Current used pesticides (Difocol,

Pentachlorophenol/anisole, etc.)

- Mono-dibutylins

- PACs (e.g. nitro-PAHs, hydroxyl-PAHs, alkyl-PAHs)

- PCB11 from smelting

- Halogenated natural products (naturally formed BDEs, OH-BDEs, MeO-BDEs, brominated dioxins, etc.)

- Microplastics

Figure 4. Chemicals of emerging Arctic concern; new POPS and products that behave like POPS. (AMAP Assessment 2016: Chemicals of Emerging Arctic Concern)

\section{Heavy metals}

At the outset AMAP focused on heavy metals, but the first assessment (AMAP, 1998) clearly demonstrated that the metal problem was mainly associated with mercury $(\mathrm{Hg})$ and lead $(\mathrm{Pb})$. For lead, analyses of

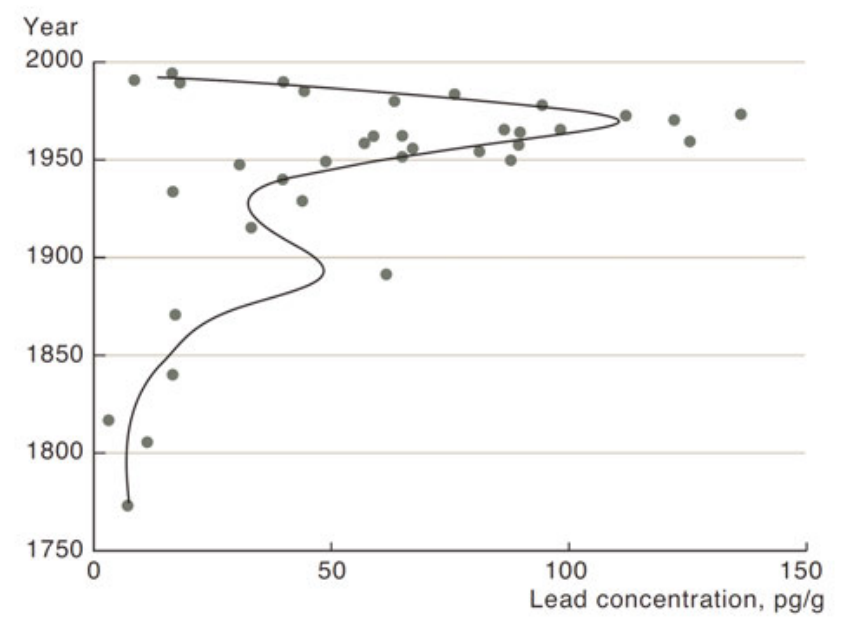

Figure 5. The variation of lead $(P b)$ in ice core from Greenland reflecting global emissions, especially due to the use of leaded gasoline from 1947 to 2000). Analyses of Ice cores can tell the story of global emissions of gases and metals, several 100k years back in time. AMAP, 2005. AMAP Assessment 2002: Heavy Metals in the Arctic 
ice cores documented a variation reflecting its levels in the atmosphere, where it was deposited through industrial emissions and the use of leaded gasoline (Figure 5). Today, the main $\mathrm{Pb}$ threat to humans in the Arctic is as fragments in birds and animals shot with homemade lead bullets. AMAP therefore recommended stopping the use of such bullets and switching to steel bullets for hunting in the Arctic, but this regulation has not been easy to implement in routine hunting activities.

As far as mercury is concerned, the $\mathrm{Hg}$ problem in the Arctic is predominantly due to coal-burning power plants in South-East Asia, see Figure 6. Few filters, if any, can trap mercury from gaseous emissions mercury and thereby prevent it from entering the atmosphere and ultimately end up in the Arctic. The consequences of such a release were observed especially in the Faroes Islands where negative effects on humans have been detected. For instance, exposure during pregnancy has been shown to be irreversible. For other examples and more details, see the AMAP human health reports from 2003, 2009 and 2015.

The use and handling of mercury are regulated by the Minamata Convention, which is a global, legally binding document that entered into force in 2017. The results from the AMAP monitoring mentioned above indeed contributed to speed up the international negotiations leading to the convention (Platjouw et al., 2018). This paper indeed describes the evolutionary process in which scientific knowledge, herded by an intergovernmental, regional forum, was involved and formed the basis for the agreement.

Emissions to air, $\mathrm{t}$

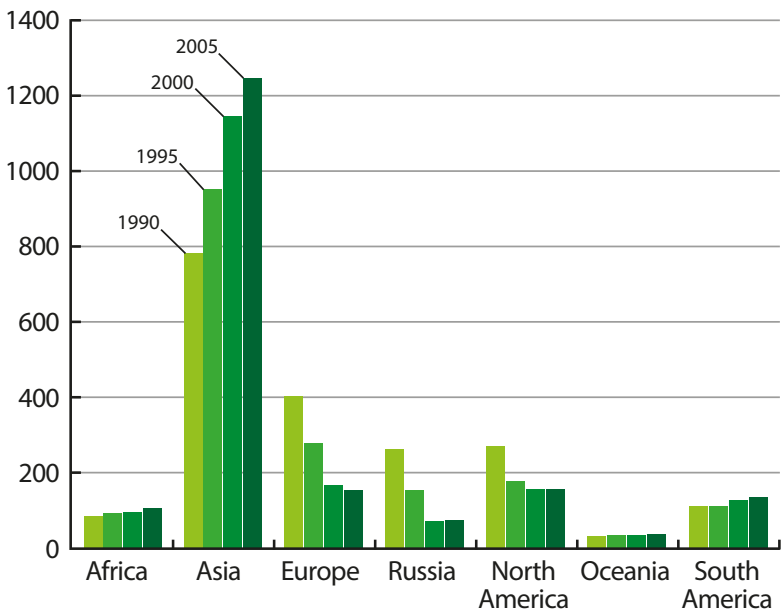

Figure 6. Global emissions of mercury. (UN-Environment. Global Mercury Assessment 2018)

\section{Climate change}

Climate issues were on the AMAP agenda from the start, and the first climate assessment was published as part of the AMAP 1998 report. This led to international cooperation, particularly with International Arctic Science Cooperation (IASC), and the Conservation of Arctic Flora and Fauna (CAFF) working group of the Arctic Council, which broadened the scope of the next assessment, Arctic Climate Impact Assessment (ACIA), published in 2005. This assessment brought both the global implications of a melting Arctic and the Arctic Council into the spotlight. There were several reasons for that: on the negative side, the report documented a "Meltdown of the Arctic", which means reduced snow and ice cover, thawing of the permafrost, global Sea Level Rise (SLR), etc; and on the positive side, new opportunities related to Arctic shipping (cargo and tourism) and accessibility of new resources such as minerals, oil, and gas. A political consequence was also observed: EU and several countries, including China, India, and Singapore, far away from the Arctic requested observer status in the Arctic Council.

These events made climate change a top priority for AMAP. Over the last decade several AMAP reports have documented the ongoing climate change and outlined the effects on Arctic ecosystems and communities, the impact on human health within the region, and climate feedbacks from the Arctic to lower latitudes. Two AMAP reports on Snow, Water, Ice and Permafrost in the Arctic (SWIPA) have significantly influenced the work of the Intergovernmental Panel on Climate Change (IPCC), for instance the results of the latest modelling of the expected temperature increase in the Arctic even if the Paris agreement is fully implemented (see Figure 7). The figure shows how much warmer Arctic areas may become and thereby trigger an enormous melting of snow and ice with the consequence the global sea level will rise $0.5-2 \mathrm{~m}$ by 2100 depending on where you are on the globe. For development of local and regional adaptation strategies in the North and elsewhere on the globe, it is important to use detailed seasonal scenarios to highlight the future situations at the sites in question, as Figure 8 illustrates.

It is well established that increased emission of $\mathrm{CO}_{2}$ also leads to increased acidification of the world oceans. However, the AMAP assessment has documented that in parts of the Arctic oceans, this process is faster than anywhere else due to a combination of several factors, including the larger storage capacity of $\mathrm{CO}_{2}$ in cold water than warm water, and much lower buffering capacity for acidity in Arctic surface water (less saline). 

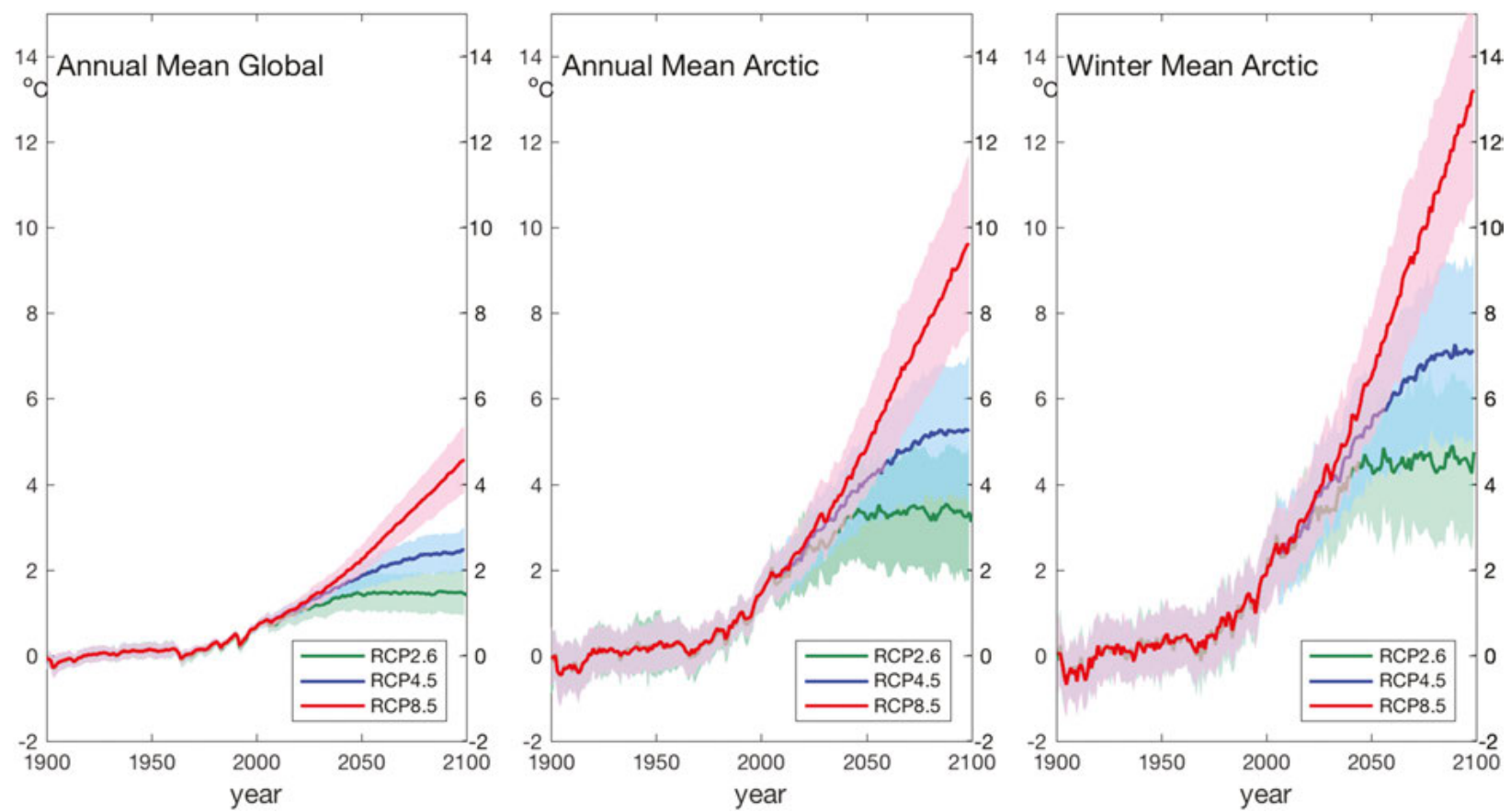

Figure 7. Projected air temperature using the three scenarios representative concentration pathway (RCP) 2.5, (close to a future $+1.5^{\circ} \mathrm{C}$ world), RCP 4.5 (close to a future $+2.5^{\circ} \mathrm{C}$ world) and $R C P 8.5$ (business as usual); to the left over the Northern hemisphere; in the middle over the Northern Hemisphere north of $60^{\circ} \mathrm{N}$; to the right the increase in November-March North of $60^{\circ} \mathrm{N}$ (Overland et al., 2018).

Over the years, AMAP has also documented that the Arctic environment and the people living there are threatened by several stress factors, which include pollutant, climate change, and a variety of human activities. In 2017, AMAP published three assessments regarding "Adaptation Actions in a Changing Arctic", analyzing combined effects of several stress factors and their influence on potential adaptation strategies to be developed and implemented within the Arctic region. An interesting observation was that for many people living in the Arctic the climate change was not seen as the most serious threat; the most important was, not surprisingly, to have a job, secure income and enough clean food for tomorrow, a clear signal to decision makers that have to satisfy short-term needs (economic and food security) in a long-term sustainable fashion (prevent climate change).

\section{Stratospheric ozone depletion}

In the first AMAP report there is a chapter on Climate change, Ozone and Ultraviolet radiation, which summarizes the long-term climatic changes on the basis of paleoenvironmental data and more recent instrumental records. It is interesting that ozone depletion is discussed because there has been much less attention to the Arctic ozone hole than the Antarctic analogue, conceivably because the depletion has been much less pronounced in the Arctic. The reason is believed to be due to differences in the stratospheric dynamics around the two poles, which are a function of temperature, aerosol contents and structural features, and the presence of anthropogenic chemicals such as chlorofluorocarbons (CFCs). CFCs play a significant role in depleting stratospheric ozone (the Ozone Layer). Over the last couple of decades CFC emissions have been considerably reduced by regulation and control introduced during the implementation of the Montreal Convention. Ozone has therefore gradually received less attention in the AMAP Monitoring Programme.

\section{Some reflections}

The scientific cooperation under AMAP has been in operation for more than 25 years with support from the governments of the Arctic Council member states, local communities in the member states, and observing countries and organizations. The results provided by AMAP have been used to provide food advice to communities in the Arctic to avoid high exposure of pollutants to humans, especially during pregnancy, and to inform international organizations like UNEP, LRTAP, and WHO about developments that calls for international regulations and actions to reduce emissions of toxic and polluting chemicals. It is also noteworthy that the AMAP program has led to increased 
scientific cooperation among the Arctic states, which in turn has played an important role in reducing the political and military tension that was so visible in the North some 30 years ago.

Several outcomes of the work made by AMAP and the experience gained in the process might be of use in other regions of the world that face similar problems with pollution and climate change, for instance in Himalaya, Africa, and South America. Some important points are as follow:

- Promoting a stable and solid scientific community that can operate independent of political influence in its daily monitoring and assessment work has shown to yield valuable and respected results.

- Scientific results should be used to create policy-relevant recommendations based on science.

- Funding must be secured for the work and that of a professional secretariat.

- Programs should be completely based on inclusive, transparent, predictable, and long-term processes and include, if possible, all relevant scientific disciplines.

- Scientists and institutions that deliver scientific data of high quality must be given due credit.

- Indigenous people and local knowledge must be included; this may be very beneficial for the design of monitoring programs.

Lars-0tto Reiersen <lars.o.reiersen@uit.no> is senior advisor to the Rector at the University of Tromsø, the Arctic University of Norway. Former executive secretary for Arctic Monitoring and Assessment Programme (AMAP).

Ramon Guardans <ramon.guardans@soundplots.com> is and advisor on POPs to the Ministry of Ecological Transition (MITECO) Madrid, Spain. Serving since 2006 as cochair of the SC Global Monitoring Plan on POPS.
Leiv K. Sydnes <leiv.sydnes@uib.no> is professor emeritus at Department of Chemistry, University of Bergen, Norway. He was president of IUPAC 20042005 and chaired the IUPAC CHEMRAWN committee in 2008-2015. In the 1990s, he was engaged in several environmental investigations in the Arctic.

\section{References}

\section{AMAP reports, see www.amap.no}

2. Daniel, A., R. Guardans and T. Harner (2018).

The Contribution of Environmental Monitoring to the Review of Effectiveness of Environmental Treaties. Environ. Sci. Technol. 52, 1-2; http://dx.doi.org/10.1021/acs.est.7b06148

3. Fiedler, H., R. Kallenborn, J. de Boer and L.K. Sydnes (2019). The Stockholm Convention: A tool for the global regulation of persistent organic pollutants (POPs). Chem. Int. 41(2), pp. 4-11; https://doi.org/10.1515/ci-2019-0202

4. Guardans R. (2012). Perspective: A note on the advantages of large-scale monitoring as in the global monitoring plan (GMP) on persistent organic pollutants (POPs). Atm. Poll. Res. 3, 369-370; https://doi.org/10.5094/APR.2012.042

5. Overland, J., E.D. Dunlea, J.E. Box, R. Corell, M. Forsius, V. Kattsov, M. Skovgård Olsen, J. Pawlak, L.-O. Reiersen and M. Wand (2018). The urgency of Arctic change, Polar Science. https://doi.org/10.1016/j.polar.2018.11.008

6. Platjouw, F.M., E.H. Steindal and T. Borch (2018). From Arctic Science to International Law: The Road towards the Minamata Convention and the role of the Arctic Council. Arctic Review of Law and Politics 9, 226-243; https://doi.org/10.23865/arctic.v9.1234

7. Stone, D. P. (2015). The Changing Arctic Environment, The Arctic Messenger. Cambridge University Press, Cambridge, UK. 360 pp; http://www.cambridge.org/9781107094413

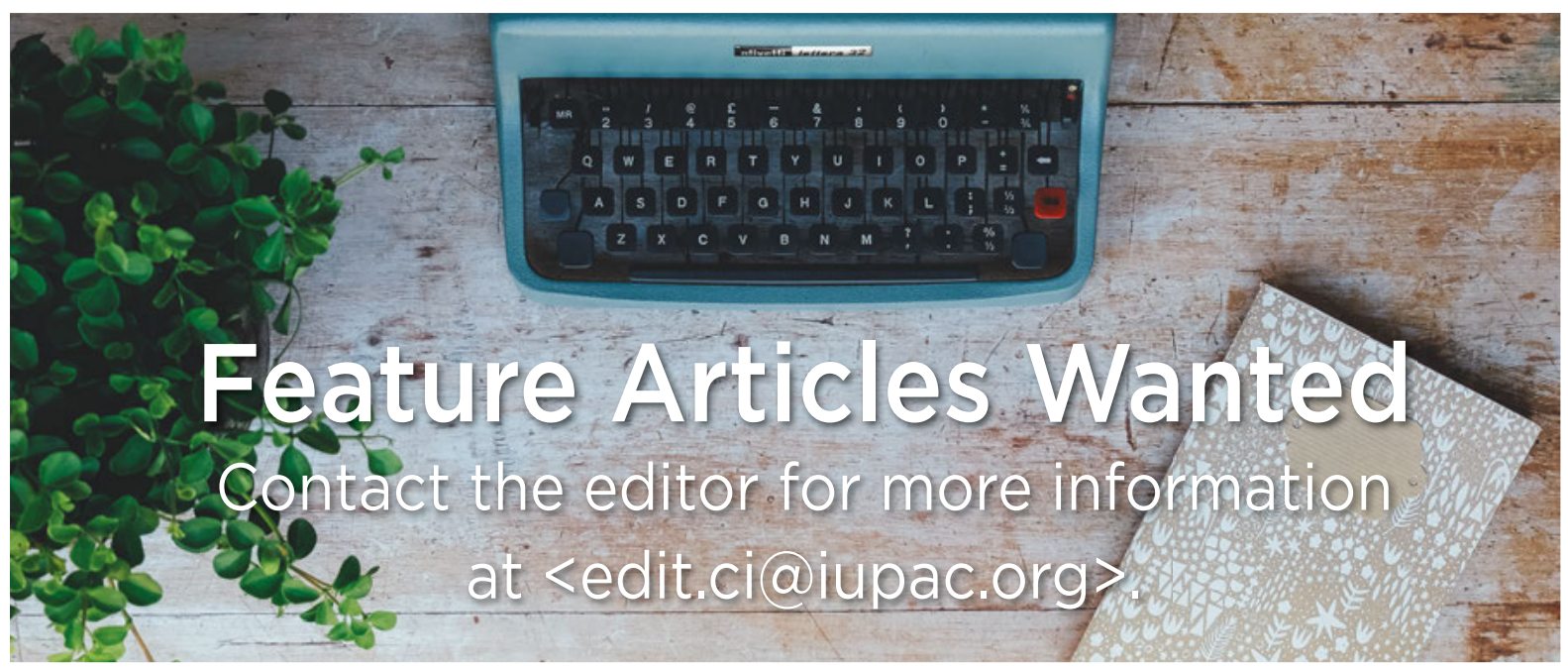

